\title{
In-situ TEM investigations on temperature-induced structural transition from monoclinic-to-cubic phase of ball-milled yttria
}

Vaishnavi Krupa B R ${ }^{1}$, Shyam Kanta Sinha ${ }^{1}$, Chanchal Ghosh ${ }^{2}$, Arup Dasgupta ${ }^{1}$, Puspendu Guha ${ }^{3}$ and P V Satyam ${ }^{4}$

${ }^{1}$ Indira Gandhi Centre for Atomic Research, Kalpakkam, Tamil Nadu, India, ${ }^{2}$ University of Connecticut, Connecticut, United States, ${ }^{3}$ Institute of Applied Physics, Seoul National University, Seoul 08826, Republic of Korea, United States, ${ }^{4}$ Institute of Physics, Sachivalaya Marg, Bhubaneswar, India

Oxide dispersion strengthened (ODS) alloys are of special interest because of their superior high temperature stability [1]. These materials bank on oxide dispersoid strengthening for which one of the key requirements is that they remain in nano-metric sizes and do not coarsen during synthesis, which involves high temperature powder consolidation process, or in service. Therefore, examination of the coarsening and phase transformation behavior of the $\mathrm{nm}$ sized oxide particles under service temperatures is an intriguing subject. In-situ TEM experiments are possibly one of the most evident method to conduct such an examination. Obviously time resolution of image acquisitions is critical in such experiments and in a TEM, this is determines by the camera used in the microscope. Equally important are the TEM holders and MEMS based holders are one of the best owing to precise control of the local environmental conditions.

Amongst all the oxide ceramics, Yttria is the most widely used owing to its low thermal expansion coefficient and thermal stability up to $\sim 2325^{\circ} \mathrm{C}$. According to phase diagram, Yttria has cubic (Ia3) structure till $\sim 2327{ }^{\circ} \mathrm{C}$, beyond that hexagonal (hP10) structure up to the melting point $\left(\sim 2400{ }^{\circ} \mathrm{C}\right)[2]$. Yttria also has a metastable monoclinic ( $\mathrm{mP} 30)$ phase, which is pressure-driven phase formation around 12-19 GPa, and it is stable on decompression [3]. Nanocrystalline yttria undergoes phase transformation from cubic to monoclinic on severe plastic deformation induced by high energy ball milling process.

In the present study, we investigate the dynamics of structural transformation upon annealing of the ballmilled yttria powder particles using in-situ transmission electron microscopy. As received milled powder shows monoclinic structure after 30 hours of milling. During annealing, it transforms from monoclinic to cubic crystal structure. The in-situ heating experiments were carried out for the 30 hours milled yttria nano powders at $500{ }^{\circ} \mathrm{C}$ and $700{ }^{\circ} \mathrm{C}$. The representative TEM bright-field images of as-received milled powder, at $500{ }^{\circ} \mathrm{C}$ and $700{ }^{\circ} \mathrm{C}$ are shown in Figure $1(\mathrm{a}-\mathrm{c})$, and the corresponding SAED pattern are shown in Figure 1(d-f), respectively. The size of as-milled yttria powder particles is in the order of $\sim 5-10 \mathrm{~nm}$ at room temperature (indicated by a circle in figure 1(a)). Annealing of these particles to the higher temperature facilitated atomic diffusion through the supporting TEM membrane. Further experiments are in progress to understand the structural changes at atomic scale by combining in-situ and ex-situ experiments while ensuring a practical/ real situation in accounting for the beam effect during the data acquisitions. In other words, we are making an attempt to consider the effect of reducing environment inside TEM column as well as high energy electron beam bombardment in data interpretation. All of the above will be presented in the conference. 


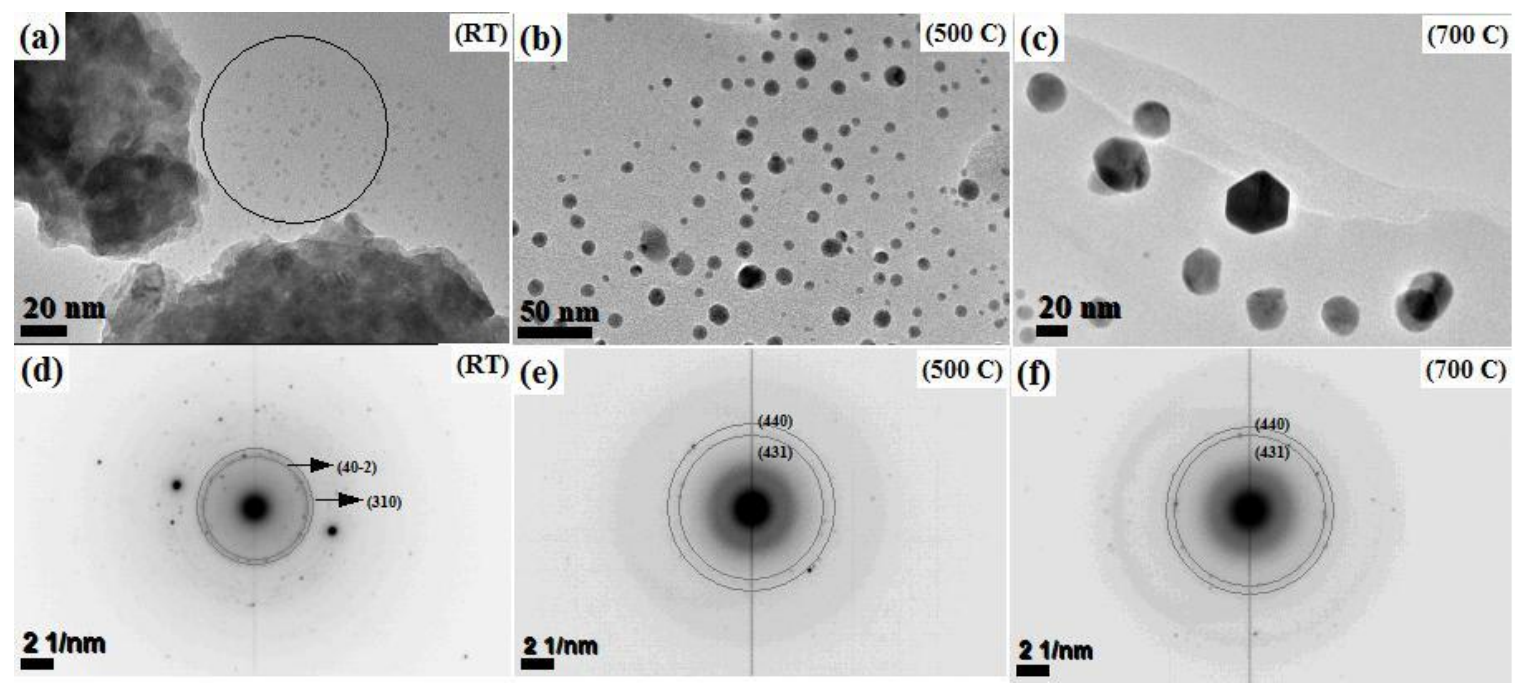

Figure 1. (a-c) TEM BF micrograph of as received 30 hours ball milled yttria powder, heated at $500{ }^{\circ} \mathrm{C}$ and $700{ }^{\circ} \mathrm{C},(\mathrm{d}-\mathrm{f})$ corresponding SAED patterns, respectively

\section{References}

[1] S. Karak, J.D. Majumdar, W. Lojkowski, A. Michalski, L. Ciupinski, K. Kurzydłowski and I. Manna, Philosophical Magazine 92 (2012) p. 516.

[2] O-Y Binary Phase Diagram 0-100 at.\% Y: Datasheet from "PAULING FILE Multinaries Edition - 2012" in SpringerMaterials (https://materials.springer.com/isp/phasediagram/docs/c_0104182), software available at URL|. [3] E. Husson, C. Proust, P. Gillet and J. Itie, Materials research bulletin 34 (1999) p. 2085. 